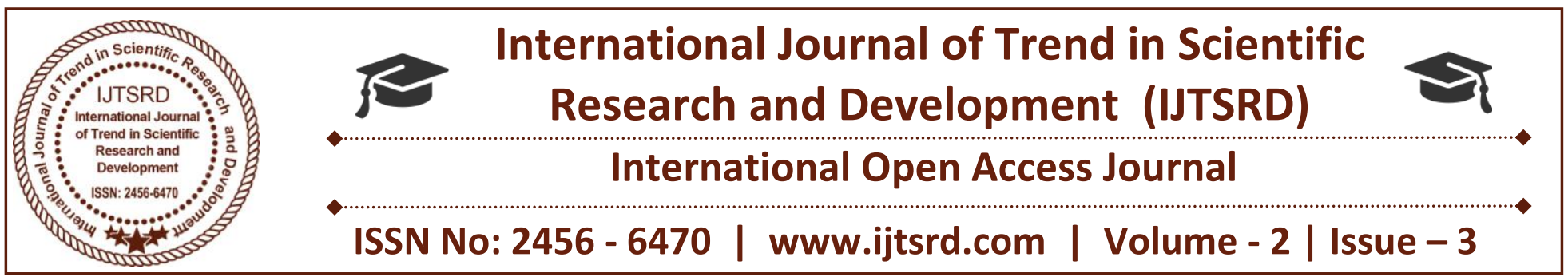

\title{
The Effect of Homemade Drink on Exercise Endrance Time in Young Adult Females
}

\author{
Okonkwo, C. O. J \\ Department of Human Physiology, Faculty of Basic \\ Medical Sciences, College of Medicine, Nnamdi \\ Azikiwe University, Nnewi Campus, Okofia,
} Anambra State, Nigeria
Oguaka V.N.

Department of Human Biochemistry, Faculty of Basic Medical Sciences, College of Medicine, Nnamdi Azikiwe University, Nnewi Campus, Okofia, Anambra State, Nigeria

\section{ABSTRACT}

Mbachu, $\mathbf{P}$

Department of Human Physiology, Faculty of Basic Medical Sciences, College of Medicine, Nnamdi Azikiwe University, Nnewi Campus, Okofia, Anambra State, Nigeria

When exercising for a very long period of time, sweating will occur and other physiological responses such as dehydration, decrease blood glucose, increase in heart rate, loss of electrolytes, fatigue etc which will lead to a decrease in exercise performance. Hence, there is an important function of rehydrating the body with fluids (sport drinks) containing electrolytes and carbohydrates to improve exercise endurance and performance. In this study examined the effects of effect of home made fruit drink (coconut and pineapple) on exercise endurance time of young adult females, (age: 17-26 years) of their height ranges (1.53-1.74 meters), weight ranges (42-98kg) and their BMI ranges $\left(16.41-35.25 \mathrm{~kg} / \mathrm{m}^{2}\right)$ jogged at designated points for 45 minutes. After the 45 minutes exercise, they rested for 10 minutes and were administered the different drinks (control 1(water), control 2 (lucozade sport drink) and test sample (home-made coconut-pineapple fruit drink)). After administering the drinks, their heart rates and blood pressures were taken and measured then they rested for 5 minutes. After a period of rest for 15 minutes in total, they continued the exercise till they were exhausted. The result indicated that the home made coconut-pineapple fruit drink observed to have an effect on the endurance time as well as the lucozade sport isotonic drink, while water was observed not to improve the endurance time.

Keywords: Dehydration, exhaustion, rehydration, sport drinks

\subsection{BACKGROUND OF STUDY}

During physical activity, heat is generated as a byproduct of muscle activity and energy metabolism (Wilmore JL, Costill DL (1994)). This heat is dissipated through sweating, where evaporation of 1 gram of water from the skin removes approximately 0.6 kilocalories of heat (Nadel ER. (1988)). However, sweating often results in dehydration, and sweat losses during heavy exercise in the heat may be as high as 2 to 3 L.h-1 (Maughan RJ, Leiper JB (1994)). Dehydration can partially disable the cardiovascular system and considerably reduce the performance (Johnson HL. (1995)). Thus, it is essential to replace the lost fluid and to maintain hydration for optimal performance (Erickson DG. (1983)). However, other drinks such as fruit drinks, caffeine free nonalcoholic fluids have been used as fluid replacement during exercise (Shi Xiacoai et al., (1995)). Physical exercise is any bodily activity that enhances or maintains physical fitness and overall health and wellness 
(Kylasov A, Gavrov S (2011)). It is performed for various reasons, including increasing growth and development, preventing ageing, strengthening muscles and the cardiovascular system, honing athletic skills, weight loss or maintenance and also enjoyment. Frequent and regular physical exercise boosts the immune system and helps prevent "diseases of affluence" such as cardiovascular disease, type 2 diabetes, and obesity (Hu FB, et al., (2001). It may also help prevent stress and depression, increase quality of sleep and act as a nonpharmaceutical sleep aid to treat diseases such as insomnia, help promote or maintain positive selfesteem, improve mental health, maintain steady digestion and treat constipation and gas, regulate fertility health and augment an individual's sex appeal or body image, which has been found to be linked with higher levels if self-esteem (Gale Encyclopedia of Medicine (2008)). Some care providers call exercise the "miracle" or "wonder" drug-alluding to the wide variety of benefits that it can provide for many individual (Pimlott N (2010)). The goal of fluid replacement during exercise is to prevent extreme dehydration, to minimize changes in electrolyte balance and to maintain optimum performance. The electrolytes present in sweat serve three major functions: controlling water movement, maintaining the acid-base balance required for cell activity and providing the micronutrients necessary for the body (America college of sport medical et al.,(2007)).

\subsection{STATEMENT OF PROBLEM}

In general, exercises have positively influenced health in many studies. Research on the impact of fruit drinks is primarily conducted among young adult females.

Fluid replacement during and after exercise is an important consideration in the successful incorporation of physical activity into a health lifestyle. While a good portion of exercisers rely on prepared sport beverages, there are other consumers that may prefer alternative methods of hydration. Diluted fruit juice can provide the nutrients that are found in juices. Individuals may want to adjust their lifestyle choices to incorporate more natural foods (fruit juice) as well as assess the financial cost of fluid replacement.

\subsection{AIMS AND OBJECTIVES}

This study is aimed at ascertaining the effect of fruit drink on exercise endurance time of young adults with the following objectives:

I. To compare the duration of time of the young females

II. To compare the effect of fruit drink, water and sport drink on exercise endurance.

\subsection{SCOPE OF STUDY}

The prospective population- based study comprising of 40 Nigerian young adults from University of Calabar, Calabar, Cross river state.

\subsection{SIGNIFICANCE OF STUDY}

This study will aid in the use of fruit drinks as sport drinks based in its effect in boosting their exercise endurance time. The findings from this study will also serve as a source of information for future researches.

\subsection{FRUIT DRINKS}

Fluid intake during prolonged exercise is effective in improving exercise performance and delaying the onset of fatigue (Below PR (1995)). To sustain high rate of work output or exercise performance in heat requires availability of carbohydrate $(\mathrm{CHO})$ as fuel for the working muscle. During physical activity, heat is generated as a by-product of muscle activity and energy metabolism (Wilmore JL, Costill DL (1994)). This heat is dissipated through sweating, where evaporation of 1 gram of water from the skin removes approximately 0.6 kilocalories of heat (Nadel ER. (1988)). However, sweating often results in dehydration, and sweat losses during heavy exercise in the heat may be as high as 2 to 3 L.h-1 (Maughan RJ, Leiper JB (1994)). Dehydration can partially disable the cardiovascular system and considerably reduce the performance (Johnson HL. (1995)). Thus, it is essential to replace the lost fluid and to maintain hydration for optimal performance (Erickson DG. (1983)). However, other drinks such as fruit drinks, caffeine free nonalcoholic fluids have been used as fluid replacement during exercise (Shi Xiacoai et al., (1995)). However, other drinks such as fruit drinks, caffeine free and nonalcoholic fluids have been used as fluid replacement during exercise.

Fruit drinks are sweetened beverages of diluted fruit drinks. There are different kinds of fruits which are 
being processed into drinks examples include oranges, pineapple, coconut, mangoes etc. Natural fruit drinks such as young coconut water (Ismail I, Singh R, Siri Singh RG. (2007)), honey (Earnest CP et al., (2004)) and milk (Watson P et al., (2008)) have been shown to be effective hydration drinks.

\subsubsection{COCONUT FRUIT DRINK AND ITS NUTRITIVE VALUES}

\subsubsection{ORIGIN}

The origin of the plant is, after many decades, still the subject of debate (Perera et al., (2009)). It has generally been accepted that the coconut originated in the Indian-Indonesia region and float-distributed itself around the world by riding ocean currents (Perera et al., (2009)). The similarities of the local names in the Malay-Indonesian region is also cited as evidence that the plant originated in the region. For example, the Polynesian and Melanesian term niu and the Philippine and Guamanian term niyog is said to be based on the Malay word nyiur or nyior (Ahuja SC, Ahuja Siddharta, Ahuja Uma (2014)).

\subsubsection{DESCRIPTION}

Plant: Cocos nucifera is a large palm, growing up to $30 \mathrm{~m}(98 \mathrm{ft})$ tall, with pinnate leaves $4-6 \mathrm{~m}(13-20 \mathrm{ft})$ long, and pinnae 60-90 cm long; old leaves break away cleanly, leaving the trunk smooth. Coconuts are generally classified into two general types: tall and dwarf (T. Pradeepkumar, B. Sumajyothibhaskar, and K.N. Satheesan (2008)).

Fruit: Like other fruits, it has three layers: the exocarp, mesocarp, and endocarp. The exocarp and mesocarp make up the "husk" of the coconuts. The mesocarp is composed of a fiber, called coir, which has many traditional and commercial uses. The shell has three germination pores (micropyles) or "eyes" that are clearly visible on its outside surface once the husk is removed. A full-sized coconut weighs about $1.44 \mathrm{~kg}(3.2 \mathrm{lb})$. It takes around 6,000 full-grown coconuts to produce a tonne of copra (Bourke, R. Micheal and Tracy Harwood (2009)).

Roots: Unlike some other plants, the palm tree has neither a tap root nor root hairs, but has a fibrous root system (Thampan P.K. (1981)). Only a few of the roots penetrate deep into the soil for stability. This type of root system is known as fibrous or adventitious.

\subsubsection{SCIENTIFIC CLASSIFICATION}

Kingdom: Plantae

(unranked): Angiosperms

(unranked): Monocots

(unranked): Commelinids

Order: Arecales

Family: Arecaceae

Subfamily: Arecoideae

Tribe: Cocoeae

Genus: $\quad$ Cocos

Species: Cocos nucifera

\subsubsection{NUTRITIONAL CONTENTS}

Per 100-gram serving with 354 calories, raw coconut meat supplies a high amount of total fat (33 grams), especially saturated fat $(89 \%$ of total fat) and carbohydrates $(24 \mathrm{~g})$ (table). Micronutrients in significant content include the manganese, iron, phosphorus, and zinc and water $(46.99 \mathrm{~g})$.

\subsubsection{GEOGRAPHICAL DISTRIBUTION}

The coconut has spread across much of the tropics, probably aided in many cases by seafaring people. Coconut fruit in the wild are light, buoyant, and highly water resistant. It is claimed that they evolved to disperse significant distances via marine currents (Foale, Mike (2003)). However, it can also be argued that the placement of the vulnerable eye of the nut (down when floating), and the site of the coir 'cushion' are better positioned to ensure that the water-filled nut doesn't fracture when dropping on rocky ground, rather than for flotation.

\subsubsection{PINEAPPLE FRUIT DRINK AND ITS NUTRITIVE VALUES}

\subsubsection{ORIGIN}

The plant is indigenous to South America and is said to originate from the area between southern Brazil and Paraguay (Morton, Julia F (1987)).

\subsubsection{DESCRIPTION}

The pineapple (Ananas comosus) is a tropical plant with an edible multiple fruit consisting of coalesced berries, also called pineapples and the most economically significant plant in the Bromeliaceae family (Coppens d'Eeckenbrugge, G. Leal, F. (2003)). 


\subsubsection{SCIENTIFIC CLASSIFICATION}

Kingdom: Plantae

(unranked): Angiosperms

(unranked): Monocots

(unranked): Commelinids

Order: $\quad$ Poales

Family: Bromeliaceae

Subfamily: Bromelioideae

Genus: $\quad$ Ananas

Species: A. comosus

\subsubsection{NUTRITIONAL CONTENTS}

In a 100-gram serving, raw pineapple is an excellent source of manganese (44\% Daily Value [DV]) and vitamin C $(58 \% \mathrm{DV})$, but otherwise contains no essential nutrients in significant quantities and water $(86.00 \mathrm{~g})$.

\subsection{EXERCISE}

Physical exercise is any bodily activity that enhances or maintains physical fitness and overall health and wellness (Kylasov A, Gavrov S (2011)). It is performed for various reasons, including increasing growth and development, preventing ageing, strengthening muscles and the cardiovascular system, honing athletic skills, weight loss or maintenance and also enjoyment. Frequent and regular physical exercise boosts the immune system and helps prevent "diseases of affluence" such as cardiovascular disease, type 2 diabetes, and obesity (Hu FB, et al., (2001). It may also help prevent stress and depression, increase quality of sleep and act as a nonpharmaceutical sleep aid to treat diseases such as insomnia, help promote or maintain positive selfesteem, improve mental health, maintain steady digestion and treat constipation and gas, regulate fertility health and augment an individual's sex appeal or body image, which has been found to be linked with higher levels if self-esteem (Gale Encyclopedia of Medicine (2008)).

\subsubsection{CLASSIFICATION}

Physical exercises are generally grouped into three types, depending on the overall effect they have on the human body (National Institute of Health, National Heart, Lungs and Blood Institute (2006)).

Aerobic exercise is any physical activity that uses large muscle groups and causes the body to use more oxygen than it would while resting (National Institute of Health, National Heart, Lungs and Blood
Institute (2006)). The goal of aerobic exercise is to increase cardiovascular endurance (Wilmore J., Knuttgen H. (2003)). Examples of aerobic exercise include running, cycling, swimming, brisk walking, skipping rope, rowing, hiking, playing tennis, continuous training, and long slow distance training (National Institute of Health, National Heart, Lungs and Blood Institute (2006)).

$>\quad$ Anaerobic exercise, which includes strength and resistance training, can firm, strengthen, and tone muscles, as well as improve bone strength, balance, and coordination.[12] Examples of strength moves are push-ups, pull-ups, lunges, and bicep curls using dumbbells (National Institute of Health, National Heart, Lungs and Blood Institute (2006)). Anaerobic exercise also include weight training, functional training, eccentric training, Interval training, sprinting, and high-intensity interval training increase short-term muscle strength (De Vos N et al., (2005))

> Flexibility exercises stretch and lengthen muscles. Activities such as stretching help to improve joint flexibility and keep muscles limber (National Institute of Health, National Heart, Lungs and Blood Institute (2006)). The goal is to improve the range of motion which can reduce the chance of injury (O’Connor D, Crowe M., Spinks W. (2005)).

Physical exercise can also include training that focuses on accuracy, agility, power, and speed. Sometimes the terms 'dynamic' and 'static' are used. 'Dynamic' exercises such as steady running, tend to produce a lowering of the diastolic blood pressure during exercise, due to the improved blood flow. Conversely, static exercise (such as weight-lifting) can cause the systolic pressure to rise significantly (during the exercise) (de Souza Nery S et al., (2010))

\subsubsection{INTENSITY OF EXERCISE}

Exercise intensity refers to how much energy is expended when exercising. Perceived intensity varies with each person. It has been found that intensity has an effect on what fuel the body uses and what kind of adaptations the body makes after exercise. Intensity is the amount of physical power (expressed as a percentage of the maximal oxygen consumption) that the body uses when performing an activity. For example, exercise intensity defines how hard the body has to work to walk a mile in 20 minutes. 


\begin{tabular}{|c|c|}
\hline Physical Activity & MET \\
\hline Light Intensity Activities & $<3$ \\
\hline Sleeping & 0.9 \\
\hline Watching television & 1.0 \\
\hline Writing, desk work, typing & 1.8 \\
\hline $\begin{array}{l}\text { Walking, } 1.7 \mathrm{mph}(2.7 \mathrm{~km} / \mathrm{h}) \text {, level } \\
\text { ground, }\end{array}$ & 2.3 \\
\hline strolling, very slow & \\
\hline Walking, $2.5 \mathrm{mph}(4 \mathrm{~km} / \mathrm{h})$ & 2.9 \\
\hline Moderate Intensity Activities & 3 to 6 \\
\hline $\begin{array}{l}\text { Bicycling, stationary, } 50 \text { watts, very light } \\
\text { effort }\end{array}$ & 3.0 \\
\hline Walking $3.0 \mathrm{mph}(4.8 \mathrm{~km} / \mathrm{h})$ & 3.3 \\
\hline $\begin{array}{l}\text { Calisthenics, home exercise, light or } \\
\text { moderate }\end{array}$ & 3.5 \\
\hline effort, general & \\
\hline Walking $3.4 \mathrm{mph}(5.5 \mathrm{~km} / \mathrm{h})$ & $3.6 \mathrm{C}$ \\
\hline $\begin{array}{l}\text { Bicycling, <10 mph }(16 \mathrm{~km} / \mathrm{h}) \text {, leisure, to } \\
\text { work }\end{array}$ & 4.0 \\
\hline or for pleasure & \\
\hline Bicycling, stationary, 100 watts, light effort & 5.5 \\
\hline Vigorous Intensity Activities & $>6$ \\
\hline Jogging, general & 7.0 \\
\hline Calisthenics (e.g. pushups, situps, pullups, & 8.0 \\
\hline jumping jacks), heavy, vigorous effort of & reno \\
\hline Running jogging, in place & 8.0 \\
\hline Rope jumping & $10.0^{\circ}$ \\
\hline
\end{tabular}

\section{Intensity Levels}

Exercise is categorized into three different intensity levels. These levels include low, moderate, and vigorous and are measured by the metabolic equivalent of task (aka metabolic equivalent or METs). The effects of exercise are different at each intensity level (i.e. training effect). Recommendations to lead a healthy lifestyle vary for individuals based on age, weight, and existing activity levels. "Published guidelines for healthy adults state that 2060 minutes of medium intensity continuous or intermittent aerobic activity 35 times per week is needed for developing and maintaining cardiorespiratory fitness, body composition, and muscular strength." (Elmahgoub, et al., (2011)).

\subsubsection{ENDURANCE TIME IN EXERCISE}

Endurance exercise is a common type of training for athletes and people that simply want to stay in shape. This type of conditioning is classified as exercise that is low in intensity but prolonged in time. Endurance activities of that scale require intense training, and some trainers and athletes argue that a specific diet is even more important. In endurance exercise, individuals are advised to have a high carbohydrate diet as this will increase the glucose level which is used as fuel.

\subsection{EFFECTS OF COCONUT-PINEAPPLE FRUIT DRINK ON EXERCISE ENDURANCE TIME}

Fruit drinks can be used to enhance exercise endurance time due to the fact that they may contain carbohydrates, essential minerals, vitamins and water at a high percentage. These are essential for providing glucose which will be used as refuel the muscles, rehydrating the body fluid which is lost as sweating and replacing the electrolytes lost during intense exercise for a longer period of time.

COCONUT WATER: Coconut water serves as a suspension for the endosperm of the coconut during its nuclear phase of development. It is used as refreshing and agreeable drink and as a useful substitute for saline glucose in intravenous infusion. It increases bold circulation in the kidney and cause profuse dieresis. For every per 100-gram serving, coconut water contains 19 calories and no significant content of essential nutrients, it provides 19 calories in a $100 \mathrm{ml}$ amount, coconut water is $95 \%$ water and $4 \%$ carbohydrates, with proteins and total fat content under $1 \%$ each. It contains no vitamins and dietary minerals in significant content.

PINEAPPLE DRINK: It is used as a refreshing drink. In a 100-gram serving, raw pineapple is an excellent source of manganese (44\% Daily Value [DV]) and vitamin C $(58 \%$ DV), but otherwise contains no essential nutrients in significant quantities (see table) and water $(86.00 \mathrm{~g})$

\subsection{MATERIALS}

The instruments used for data collection were:

Standard weighing scale with standiometer

Stethoscope

Sphygmomanometer

Stopwatch

Sport drinks:

\section{Water}

II. Lucozade sport isotonic drink

III. Home-made coconut-pineapple fruit drink 
International Journal of Trend in Scientific Research and Development (IJTSRD) ISSN: 2456-6470

\subsection{LOCATION OF STUDY}

The location of study is a Federal Institution of Nigeria, University of Calabar, Calabar, Cross river state with an estimated population of over 1500 students.

\subsection{PARTICIPANTS}

The study was performed on a sample of students from the aforementioned Nigerian University population. The participants were young adults within the age bracket of 17-26 years, they were predominantly females: 10 females were grouped into CONTROL 1 (WATER), 10 females were grouped into CONTROL 2 (LUCOZADE SPORT ISOTONIC DRINK), and 15 females were grouped into TEST (Homemade coconut-pineapple fruit drink), thus a total of thirty-five individuals were used in the study.

Healthy individuals were recruited from the school community, with no formal history of medical diagnosis and/or treatment of hypertension, neurological diseases, psychological disorder, diabetes, and infection, cardiovascular or respiratory disorders that would pose a risk during the test or could impair the collection of data or result.

Participants were recruited using word-of-mouth, phone messages and calls, most of the participants were recruited through their course-reps who called a meeting with their colleagues concerning the present study. After selection, subjects were contacted and the purpose of the study was explained, thus care was taken to avoid selecting a population of non-participants. Further selection was performed if a subject refused to participate or was excluded, this continued until the desired number of 35 subjects was achieved.

Participants selected were young adults within the age bracket of 17-26 years with correct hearing and visual abilities, non-athletes, non-smokers, non-pregnant, nonalcoholics, non-diabetes, non-asthmatics, nonhypertensive, apparently healthy and free of cardiovascular or respiratory diseases and not taking any medications that could affect the test to be carried out.

Informed consent was obtained from all the subjects and ethical approval was received from the ethical committee of Basic Medical Sciences Nnamdi Azikiwe University, College of Health Sciences, Nnewi campus.

\subsection{STUDY DESIGN}

This study was designed to determine the effect of homemade fruit drink on exercise performance of young adults. This was a correlative, comparative, and prospective study involving human subjects recruited from a cross- section of young students at the aforementioned university, all testing was conducted in Abraham Odiah Stadium.

\subsection{PROCEDURE}

\section{MEASUREMENT OF BASELINE CHARACTERISTICS OF PARTICIPANTS}

In this study, two variables were measured Blood Pressure and Heart rate using the stethoscope and the mercurial sphygmomanometer. The participants wore loose- fitting sport clothes for easy pushing up of sleeves. Before the readings were taken, the participants sat down quietly on a bench and rested for at least five minutes, with their left arm resting on a firm, flat surface, their palm facing upwards and also their feet flat on the floor (legs uncrossed)., The cuff was kept at the same level as the heart during measurement; the readings shown on the mercury glass tube were recorded. Their heart rates were measured using the stethoscope and the timing was recorded using a stop watch.

\section{ANTHROPOMETRIC MEASUREMENTS:}

Anthropometric measurements such as height (stretch stature) and weight were recorded. Height was measured to the nearest $0.5 \mathrm{~cm}$ with using a height scale or Haespenden standiometer. The body weight was measured to the nearest $0.1 \mathrm{~kg}$ using a weighing scale which was placed on a firm flat surface with the subjects wearing light weight clothe, with no shoes on they stood on the standiometer with their feet together and kneels straight and looking straight ahead. Body mass index was calculated using Quetulet formula $\mathrm{BMI}=$ weight (kg)/ height $(\mathrm{m} 2)$.

\section{PREPARATION OF THE COCONUT-PINEAPPLE FRUIT DRINK}

Three coconuts were cut to extract the coconut water which measured up to $100 \mathrm{ml}$. three ripe pineapples were selected and washed. After the fruits were washed, they were peeled. The juice was extracted by cutting the flesh of the pineapples into tiny cuts and blended. After the juice was filtered, coconut water was added to the filtrate. The filtrate was diluted with $300 \mathrm{ml}$ of water to reduce the concentration of the juice. The reason for its dilution is that "Research has shown that a sports drink made up of $4-8 \%$ carbohydrates $(4-8 \mathrm{~g} / 100 \mathrm{~mL})$ is emptied by the stomach most efficiently and absorbed 
International Journal of Trend in Scientific Research and Development (IJTSRD) ISSN: 2456-6470

more easily by the small intestine (sportmedbc.com (2017)).

\section{AEROBIC EXERCISE (JOGGING)}

PRE-EXERCISE: the heart rates and blood pressures of the individuals were taken and measured before they performed the exercise. They jogged for 45 minutes at designated points.

RESTING PERIOD: after exercising for 45 minutes, they rested for 10 minutes and were administered the different drinks control 1 (water)[250ml], control 2 (lucozade sport isotonic drink)[250ml] and test sample (home-made coconut-pineapple fruit drink)[250ml]. After administration of the drinks, their heart rates and blood pressures were taken and measured. When those measurements were taken, they rested for 5 minutes.

ENDURANCE TIME: after a period of rest for 15 minutes, they continued the exercise till they were exhaustion.

\subsection{DATA ANALYSIS}

All analysis was conducted using SPSS software version 20.0 using Analysis of variance (ANOVA) and presented in mean \pm standard deviation form. Variables were adjusted for sex, height and age. Statistical significance was reported at the $\mathrm{p}<0.05$ level. The probability of a type 1 error was established as 0.05 for all tests. Spearman's correlation was used to analyze the relationship between water, lucozade sport isotonic drink and coconut-pineapple fruit drink.

\subsection{COMPARISONS OF HOME-MADE}

COCONUT-PINEAPPLE FRUIT DRINK AMONG LUCOZADE SPORT ISOTONIC DRINK AND WATER

The table data indicates that there was no significant effect observed in the mean endurance time of water when compared to the coconut-pineapple fruit drink and lucozade sport isotonic drink. There was a significant increase in the endurance time of both the lucozade sport isotonic and the coconut-pineapple fruit drink, but the significant was more in the coconut-pineapple fruit drink.

\begin{tabular}{|l|ll|l|l|}
\hline & $\begin{array}{l}\text { Mean } \pm \\
\text { SEM }\end{array}$ & P-value & F-value \\
\hline $\begin{array}{l}\text { Coconut- } \\
\text { pineapple fruit } \\
\text { drink }\end{array}$ & $\begin{array}{l}7.40 \quad \pm \\
0.28\end{array}$ & & \\
\hline Water & $4.50 \quad \pm$ & 0.008 & 19.906 \\
& $0.49 \quad$ & & \\
\hline $\begin{array}{l}\text { Lucozade sport } \\
\text { isotonic drink }\end{array}$ & $\begin{array}{lll}7.05 \\
\text { is }\end{array}$ & 0.130 & \\
\hline
\end{tabular}

Table 1.0: COMPARISONS OF HOME-MADE COCONUT-PINEAPPLE FRUIT DRINK AMONG LUCOZADE SPORT ISOTONIC DRINK AND WATER

\subsection{DISCUSSION}

Hydration is important for the optimal performance for all athletes. Athletes who develop a systematic method of ensuring they are consistently hydrated have better recovery and higher energy levels. When athletes are adequately hydrated, their bodies are able to transport nutrients and oxygen to working muscles and aid muscle repair, remove lactic acid build up, eliminate nitrogenous waste and regulate body temperature. Losing as little as two percent of body weight through sweat can impair an athlete's ability to perform due to a low blood volume and less than optimal utilization of nutrients and oxygen.

Sport drinks have been researched extensively and generally provide an excellent alternative to plain water for hard working athletes. During intensive aerobic exercise, the body's preferred source of fuel is carbohydrate (rather than protein or fat) due to the efficiency of energy transfer to fatigued muscles. The majority of sport drinks are formulated to deliver carbohydrates, electrolytes and fluids in such a way that will minimize stomach upset and maximize intestinal absorption for delivery of energy to muscles.

From this study, it can be deduced that diluted fruit drink may have an effect on endurance time as well as lucozade sport isotonic drink (sport beverages) which correlates with the research on "The Effects of Ingestion of Sugarcane juice and Commercial Sport Drinks on Cycling Performance of Athletes In Comparison to Plain Water" which concluded that Sugarcane juice may be equally effective as Sport Drink and Plain Water during execise in a comfortable environment $(<300 \mathrm{C})$ and as effective a rehydration drink as Sport Drink and Plain Water (Kommi Kalpana et al., (2012)). 
International Journal of Trend in Scientific Research and Development (IJTSRD) ISSN: 2456-6470

\subsection{LIMITATIONS}

This study could assess the rehydration time only up to 15 minutes and exhaustion time. This study did not assess the serum electrolyte after exercise, blood lactate level after exercise, total body water during and after exercise, maximum oxygen consumption during exercise and blood glucose level after exercise.

\subsection{CONCLUSION}

This result presented broaden the literature published on beverages utilization in physical exercise and provides consumers insight into alternative to prepared sport drinks. The home-made coconut-pineapple fruit drink was observed to have an effect on the endurance time as well as the lucozade sport isotonic drink, while water was observed not to improve the endurance time.

\section{REFERENCES}

1. Ahuja, SC; Ahuja, Siddharta; Ahuja, Uma (2014). "Coconut - History, Uses, and Folklore" (PDF). Asian Agri-History. 18 (3): 223. Retrieved 3 January 2017.

2. American College of Sports Medicine, Sawka MN, Burke LM, Eichner ER, Maughan RJ (2007) American College of Sports Medicine position stand. Exercise and fluid replacement. Med Sci Sports Exerc 39: 377-90

3. Below PR, Mora-Rodriguez R, Gonzalez-Alonso J, (1995). Fluid and carbohydrate / ingestion independently improve performance during one hour of intense exercise. Med Sci Sports Exercise;17:45661

4. Bourke, R. Michael and Tracy Harwood (Eds.). (2009). Food and Agriculture in Papua New Guinea. Australian National University. p. 327. ISBN 978-1921536-60-1.

5. Coppensd'Eeckenbrugge, G; Leal, F. (2003). "Chapter 2: Morphology, Anatomy, and Taxonomy". In Bartholomew, DP; Paull, RE; Rohrbach, KG. The Pineapple: Botany, Production, and Uses. Wallingford, UK: CABI Publishing. p. 21. ISBN 0-85199-503-9.

6. de Souza Nery S, Gomides RS, da Silva GV, de MoraesForjaz CL, Mion D Jr, Tinucci T (2010-0301). "Intra-Arterial Blood Pressure Response in Hypertensive Subjects during Low- and HighIntensity Resistance Exercise". Clinics. 65 (3): 2717. PMC 2845767 . PMID 20360917. doi:10.1590/S1807-59322010000300006.
7. De Vos N.; Singh N.; Ross D.; Stavrinos T. (2005). "Optimal Load for Increasing Muscle Power During Explosive Resistance Training in Older Adults". The Journals of Gerontology. 60A (5): 638-647. doi:10.1093/gerona/60.5.638.

8. Earnest CP, Lancastu SL, Rasmussen RJ, (2004) Low versus high glycemic index meals carbohydrate gel ingestion during stimulated $64 \mathrm{~km}$ cycling time performance. J Str Cond Res;18:466-72.

9. Elmahgoub, S. S., Calders, P., Lambers, S., Stegen, S. M., Van Laethem, C., \&Cambier, D. C. (2011). The effect of combined exercise training in adolescents who are overweight or obese with intellectual disability: The role of training frequency - Journal of Strength and Conditioning Research , $25(8), 1$.

10. Erickson DG. (1983) Fluid and Electrolytes in Endurance Training. In: Appenzeller O, Atkinson R, editors. Sports Medicine — Fitness, Training and Injuries. USA: Urban \&Schwarzenberg, Inc;. p. 157.

11. Foale, Mike. (2003). The Coconut Odyssey - the bounteous possibilities of the tree of life. Australian Centre for International Agricultural Research. Retrieved May 30, 2009.

12. Gale Encyclopedia of Medicine. (2008): "Strengthening exercise increases muscle strength and mass, bone strength, and the body's metabolism. It can help attain and maintain proper weight and improve body image and self-esteem". "Exercise" medical-dictionary.thefreedictionary.com.

13. Hu FB, Manson JE, Stampfer MJ, Colditz G, Liu S, Solomon CG, Willett WC; Manson; Stampfer; Colditz; Liu; Solomon; Willett (2001). "Diet, lifestyle, and the risk of type 2 diabetes mellitus in women". The New England Journal of Medicine. 345 (11): 790-797. PMID 11556298. doi:10.1056/NEJMoa010492.

14. Ismail I, Singh R, Siri Singh RG. (2007) Rehydration with sodium enriched coconut water after exercise induced dehydration. South East Asian J Tropical Med Public Health;38:764-85

15. Johnson HL. (1995)The requirements for fluid replacement during heavy sweating and the benefits of carbohydrates and minerals. In: Kies CV, Driskell JA, editors. Sports Nutrition: Mineral and Electrolytes. USA: CRC Press;. pp. 215-233.

16. Kommi Kalpana, Priti Rishi Lal, Doddipalli Lakshmi Kusumal, Gulshan Lal Khanna (2012). The 
Effects of Ingestion of Sugarcane Juice and Commercial Sports Drinks on Cycling Performance of Athletes in Comparison to Plain Water.

17. Kylasov A, Gavrov S (2011). Diversity Of Sport: non-destructive evaluation. Paris: UNESCO: Encyclopedia of Life Support Systems. pp. 462-491. ISBN 978-5-8931-7227-0.

18. Maughan RJ, Leiper JB (1994). Fluid replacement requirement in soccer. J. Sports Sci (Special Issue);12:529-53.

19. Morton, Julia F (1987). "Pineapple, Ananascomosus". Retrieved 2011-04-22.

20. Nadel ER. (1988) New Ideas for Rehydration During and After Exercise In Hot Weather. Sports Sci. Exchange;1(3)

21. National Institutes of Health, National Heart, Lung, and Blood Institute (June 2006). "Your Guide to Physical Activity and Your Heart" (PDF). U.S. Department of Health and Human Services.

22. O'Connor D.; Crowe M.; Spinks W. (2005). "Effects of static stretching on leg capacity during cycling". Turin. 46 (1): 52-56.

23. Perera, Lalith, Suriya A.C.N. Perera, Champa K Bandaranayake and Hugh C. Harries. (2009). "Chapter 12 - Coconut". In Johann Vollmann and IstvanRajcan (Eds.). Oil Crops. Springer. pp. 370372. ISBN 978-0-387-77593-7.

24. Pimlott N (May 2010). "The miracle drug". Can Fam Physician. 56 (5): 407, 409. PMC 2868602 . PMID 20463262
25. Shi Xiacoai, Summer RW, Schedl HP, Flanagan SW, Chang R, Gisolfi CV (1995). Effect of carbohydrate type and concentration of solution osmolality on water absorption." Med. Sci. Sports Exercise.;27(12):1607- 1615. [PubMed]

26. T. Pradeepkumar, B. Sumajyothibhaskar, and K.N. Satheesan. (2008). Management of Horticultural Crops (Horticulture Science Series Vol.11, 2nd of 2 Parts). New India Publishing. pp. 539-587. ISBN 978-81-89422-49-3.

27. Thampan, P.K. (1981). Handbook on Coconut Palm. Oxford \& IBH Publishing Co.

28. The President's Council on Physical Fitness and Sports-Publications. (n.d.) (2017). President's Council on Fitness, Sports \& Nutrition. Retrieved April 5, 2011, from http://www.fitness.gov/fitness.html

29. Watson P, Love JD, Maugham RJ,(2008) A comparison of the effects of milk and a carbohydrate electrolyte drink on the restoration of fluid balance and exercise capacity in a hot humid environment. Eu J Appl Physio;104:63342.

30. Wilmore J.; Knuttgen H. (2003). "Aerobic Exercise and Endurance Improving Fitness for Health Benefits". The Physician and Sportsmedicine. $31 \quad 45$ (5): doi:10.3810/psm.2003.05.367.

31. Wilmore JL, Costill DL.(1994) Physiology of Sport and Exercise. Champaign: Human Kinetics. 